\title{
Analysis of full-text publication and publishing predictors of abstracts presented at an Italian public health meeting (2005-2007)
}

\author{
S. Castaldi ${ }^{1}$, M. Giacometti ${ }^{2 *}$, W. Toigo ${ }^{1}$, F. Bert $^{2}$ and R. Siliquini ${ }^{3}$
}

\begin{abstract}
Background: In Public Health, a thorough review of abstract quality evaluations and the publication history of studies presented at scientific meetings has never been conducted. To analyse the long-term outcome of quality abstracts submitted to conferences of Italian Society of Hygiene and Public Health (SIt) from 2005 to 2007, we conducted a second analysis of previously published material aiming to estimate full-text publication rate of high quality abstract presented at Italian public health meetings, and to identify predictors of full-text publication.

Methods: The search was undertaken through scientific databases and search engines and through the web sites of the major Italian journals of Public Health. For each publication confirmed as a full text paper, the journal name, impact factor, year of publication, gender of the first author, type of study design, characteristics of the results and sample size were collected.

Results: The overall publication rate of the abstracts presented is $23.5 \%$; most of the papers were published in Public Health journals (average impact factor: 3.007). Non universitary affiliation had resulted in a lower probability of publication, while some of the Conference topics had predisposed the studies to an increased likelihood of publication as well as poster form presentation.

Conclusions: The method presented in this study provides a good framework for the evaluation of the scientific evidence. The findings achieved should be taken into consideration by the Scientific Societies during the contributions selection phase, with the aim of achieving a continuous improvement of work quality. In the future, it would be interesting to survey the abstract authors to identify reasons for unpublished data.
\end{abstract}

Keywords: Scientific Societies, Publications, Conferences and congresses

\section{Background}

In the international literature, few Medical Scientific Societies and Associations performed quality evaluations of the studies presented at their scientific meetings, but some studies have investigated distinct aspects, such as positive outcome or institutional bias, associated with acceptance at scientific meetings [1-4]; however, none of

\footnotetext{
*Correspondence: marika.giacometti@unito.it

${ }^{2}$ Department of Public Health, Post Graduated School in Public Health,

University of Turin, Via Santena 5/bis, 10126 Turin, Italy

Full list of author information is available at the end of the article
}

these associations, neither in Italy nor in other countries, is a Public Health Organization [5-8]. Moreover, most of the available papers, in addition to the abstract quality assessment, are involved in analysing the long term outcome and publication history of the works presented to congress or conferences, with the final aim of identifying factors predicting full publication [9-22]. Even this type of qualitative analysis has never been conducted in the Public Health field.

Moreover, some elements of the scientific data selection process remained unclear. Thus, with the aim of improving the understanding of the pathway of scientific data 
from congress documents to scientific evidence, some systematic reviews have been conducted [23-25].

Von Elm et al. [25] concluded that approximately onethird of abstracts submitted to biomedical meetings are eventually published as full reports. He identified five factors that possibly play a role in subsequent publication: abstracts that reported on a positive study outcome, abstracts that reported basic research, abstracts presented at meetings with a selected number of participants and abstracts submitted to United States meetings. Using survival-type analysis, he estimated that $27 \%$ were published after $2,41 \%$ after 4 and $44 \%$ after 6 years.

In Italy, there are few studies of this issue and none in the Public Health field. Vecchi et al. [26] focused on the abstracts' results and their association with the full publication of contributions presented at the Annual Meeting of College on Problems of Drug Dependence; they concluded that $62 \%$ of the abstracts were subsequently published in peer reviewed journals and that studies with positive findings were more likely to be published.

Considering these data, there is a clear need to provide to public health professional an objective analysis of the potential possibilities and achievements of the evidence discussed during a Public Health Meeting.

The Congress of the Italian Society of Hygiene (SItI) appears to be, in the Italian context, an essential moment at which scientific knowledge is made available to the scientific community, an opportunity for participants to gain experience and an important step in scientific progress. Indeed, these events promote and facilitate collaboration between research groups, and the results obtained from the Congress works are often used in decision making by all Public Health professionals.

Considering the important role played by these conferences in the dissemination of knowledge, in recent years, there has emerged a strong need to submit all the contributions sent as oral communication or posters to an evaluation process, with the aim of analysing the main characteristics and quality of work accepted and then published in the Abstract Books from 2005 to 2010. Castaldi et al. [27] developed an evaluation tool, and the results showed that the average score among all the abstracts reviewed was good. Oral communications showed an average score higher than posters, and according to the affiliation, the highest scores were associated with Universities.

Starting from the results presented by the study mentioned above [27], we have deepened our analysis to analyse more specifically the long-term outcome of good quality abstracts submitted to SItI conferences over a 3-year period (from 2005 to 2007).

Our main objectives are to estimate full-text publication rate of high quality abstract presented at Italian public health meetings, and to identify predictors of fulltext publication.

\section{Methods}

During a previous study [27], a total of 4399 abstracts presented to SItI congresses or conferences from 2005 to 2010 were analysed. As reported in this previous article, the reviewers were 11 students from the Postgraduated School in Public Health of the Universities of Turin and Milan, under the supervision of their two School Directors. The amount of agreement within the eight individual criteria of the evaluation checklist was measured by Intraclass Correlation Coefficient (ICC) [27].

The evaluation used eight items related to coherency, structure, originality of the study, definition of study objectives, definition of the type of study, description of data sources, description of results, and conclusions, discussion and practical implications of the study.

For each item, the researcher could assign marks from 0 to 3 , so the maximum total marks for each form was 24 .

Among all abstracts, only the ones evaluated as "good quality works" were selected for the present study $(\mathrm{N}=621)$. This group includes not only papers with a total score equal to or greater than 19 but also papers with a lower score (between 16 and 18) that scored well in all the items analysed but were not evaluated on one specific item (the "Inherence" item) because it belonged to the miscellaneous topic group. In this regard, the categories of topics were identified according the congress sessions groups, when available. If the themes of the sessions were not available (i.e. for the abstracts accepted as posters in 2005) we classified by a manual revision the abstracts according to the congress sessions of the other years. Following this strategy we identified 11 categories: Food and Nutrition; Health Education; Organization; Vaccines; Epidemiology of Infective Diseases; Epidemiology of Chronic Degenerative Diseases; Environment; Hospital Hygiene; Miscellaneous; Dental Hygiene. Only in the case of Abstracts relating to different subjects but not attributable to previous specific groups we decided to put them in the 'Miscellaneous' group.

After a pilot study, the publication history of each abstract presented during 2005, 2006 and 2007 meetings was determined in July 2012, enabling at least a 5-year follow-up. The search was undertaken through PubMed, MEDLINE, the Cochrane library and the web sites of the major Italian journals of Public Health and Hygiene, with no language restrictions. In order to find further papers not published on the previous databases, we decided to include Google Scholar, despite its relative limited scientific value, in our search strategy.

The first search criterion was the combination of the first author's name and keywords available in the title or 
abstract. When this search strategy did not identify any publications, to minimise errors in the follow-up, various combinations of words taken in the title and abstract, keywords and author names were tested.

The abstract was considered "published" if at least one author of the abstract was an author of the full publication and the main outcome from the abstract was an outcome in the full manuscript. A change in the sample size, the title or the name or order of some authors or minor changes to the objectives was not considered as a de novo study, whereas manuscripts describing different endpoints were considered as such.

For each publication confirmed as a full-text paper, the journal name, its impact factor and the year of publication were collected.

In the case of abstracts published more than once, we used the earliest publication. Abstracts published in full before the presentation at the Conference were excluded.

In addition, for each abstract of the sample, the following information was collected: gender of the first author (through web search engines), type of study design (experimental, observational descriptive, observational analytical, revision), characteristics of the results (positive or negative) and sample size ( $\mathrm{n} \leq 100$ or $\mathrm{n}>100)$.

All the analysis was performed using STATA-MP 11 software. We performed a descriptive statistical analysis to describe the publication history and the main characteristics of the sample.

All the abstracts characteristics that were available in the conferences databases were included, in particular: affiliation, topics, year, abstract, geographic area, first author gender, study design, results, sample size, total score. It was not performed a preventive selection of the characteristics included.

Then, a univariate logistic regression analysis was performed to test the strength of the associations hypothesised and, finally, the variables associated with a positive outcome of publication (accepted level of statistical significance: $\mathrm{p}<0.25$, according to the Hosmer-Lemeshow test) were included in a model of multivariate analysis, with the aim of identifying possible factors predicting publication and to remove any confounders [28]. We included the following variables: affiliation, topics, abstract, first author gender, study design, results, total score.

\section{Results}

Among the 4399 abstracts accepted from 2005 to 2007 by the SItI for its annual conference, only 621 abstracts were included in the analysis (31.6\%), meeting the main inclusion criteria of the study.

The main descriptive results are shown in Table 1 . Most of the works were presented in 2007 (41.9\%),
Table 1 Baseline characteristics of abstract evaluated $(\mathrm{N}=621)$

\begin{tabular}{lr}
\hline & $\%$ \\
\hline Abstract & \\
Poster & 76.0 \\
Oral & 24.0 \\
First author gender & \\
Female & 51.5 \\
Male & 48.5 \\
Affiliation & \\
University & 68.0 \\
Non Universitary hospitals & 15.0 \\
Other & 11.7 \\
Study design & \\
Local Public Health Institution & 5.3 \\
Observational analytical & 41.8 \\
Observational descriptive & 41.0 \\
Sperimental & 10.2 \\
Revision & 7.0 \\
Results & \\
Positive & 72.6 \\
Not evaluable & 20.8 \\
Negative & 6.6 \\
\hline
\end{tabular}

$30.1 \%$ in 2005 and $28 \%$ in 2006. Considering all the 3 years in study, the most represented categories of topics are Organization (19.3\%), Health education (15.6\%), Epidemiology of infectious disease (14\%) and Food and Nutrition $(10.8 \%)$. The more frequent affiliation was University (68\%), followed by Non Universitary Hospitals $(15 \%)$. Although the works were all selected for their good quality, it was decided to split them into three groups according to the total score previously achieved.

Thirty per cent of the papers reached a score between 16 and 18 (medium quality); $52.5 \%$ were high quality works that had a score between 19 and 21, while only $17.5 \%$ could be defined as very high quality works with a score between 22 and 24 .

By considering the main outcome of the study (Table 2), it can be noted that the overall publication rate of the abstracts presented is $23.5 \%$ and that most of the papers were published in Public Health journals (53.4\%). Among all the journals, $63 \%$ were peer reviewed, and the impact factor goes from 0.441 to 6.600 with an average value of 3.007 .

The average time gap between the presentation at the SItI Conferences and the publication in full text was 2.1 years.

Table 3 shows the characteristics of the papers published in full according to the most cited variables predictive of publication $[16,17,19,28,29]$. 
Table 2 Publication rates and publication history of the evaluated abstract $(\mathrm{N}=621)$

\begin{tabular}{|c|c|c|c|c|}
\hline & 2005 & 2006 & 2007 & Total sample \\
\hline Publication rate & $22.5 \%$ & $23.6 \%$ & $24.2 \%$ & $23.5 \%$ \\
\hline \multicolumn{5}{|l|}{ Journal type } \\
\hline Public health & $38.1 \%$ & $58.5 \%$ & $60.3 \%$ & $53.4 \%$ \\
\hline Other & $61.9 \%$ & $41.5 \%$ & $39.7 \%$ & $46.6 \%$ \\
\hline Peer reviewed journal & $66.7 \%$ & $58.5 \%$ & $63.5 \%$ & $63.0 \%$ \\
\hline Average impact factor & $2.75 \mathrm{Cl}(2.20-3.29)$ & $3.27 \mathrm{Cl}(2.74-3.79)$ & $3.03 \mathrm{Cl}(1.48-2.36)$ & $3.00 \mathrm{Cl}(2.63-3.43)$ \\
\hline Average time of publication gap (years) & $2.28 \mathrm{Cl}(1.73-2.83)$ & $2.54 \mathrm{Cl}(2.05-3.01)$ & $1.68 \mathrm{Cl}(1.38-1.98)$ & $2.09 \mathrm{Cl}(1.84-2.34)$ \\
\hline
\end{tabular}

The University affiliation was more associated with the publication in full text, as were some Conference topics (48.6\% Vaccine, $37 \%$ Chronic disease).

The study design (33.3\% of the experimental studies and $25.8 \%$ of the observational analytical ones) and the characteristics of the results $(9.8 \%$ of the studies with negative results and $26.9 \%$ of those with positive results) seem to be associated with the likelihood of being published.

Furthermore, the increase of the quality score assigned to the works during the evaluation phase seems to be a characteristic more associated with the subsequent publication. All these associations were supported by statistical significance $(\mathrm{p}<0.005)$. The results related to the potential highest rate of publication by females (26.4 vs $20.7 \%$; $=0.216)$ and by sample size $(24.7 \%$ of the studies with $\mathrm{n}>100$ were published in extenso compared to $21.4 \%$ of the studies with $\mathrm{n} \leq 100 ; \mathrm{p}=0.342$ ) were, instead, no statistically significant.

With the aim of testing the strength of all these associations, we carried out a univariate linear regression. Through this type of analysis, we investigated the single association between each variable and the main outcome of the study: the publication of the works in extenso.

The variables associate, with an accepted level of statistical significance ( $\mathrm{p}<0.25$, according to the HosmerLemeshow test), with a positive outcome of publication in a model of multivariate analysis. The results are shown in Table 4.

The Non Universitary Hospitals affiliation, in comparison with the University one, results in a lower probability of publication. This finding does not change in the multivariate analysis, with a corrected odds ratio of 0.09 $(\mathrm{p}<0.001)$.

Moreover, the analysis revealed some topics that predispose the studies to a statistically significant increased likelihood of publication, such as Dental hygiene (OR 10.52 , but the abstracts related to this topic were only 7 ) and Vaccine (OR 3.45).

The first author female gender is confirmed to be associated with an increased likelihood of publication (adjusted OR 1.31), but this association is not statistically significant $(\mathrm{p}=0.212)$.

Similarly, the association between a higher probability of publication and the typology of the study shows an advantage of the experimental designs over the descriptive observational studies (adjusted OR 0.74), but the statistical significance $(\mathrm{p}=0.011)$ revealed in the univariate analysis is not confirmed in the multivariate one.

Regarding the abstract quality score, a positive trend emerges: a high evaluation score means there is a higher probability the work will be published in extenso $(\mathrm{p}=0.003)$.

\section{Discussion}

As the SItI conferences represent a fundamental moment in the Italian Public Health field, we think an evaluation of potential predictors of publication on the international literature of studies presented in these meetings can represent a due starting point for suggesting improvements.

In regard to the publication rate, from the analysis, it emerged that $23.5 \%$ of the high quality abstracts presented at SItI conferences were subsequently published in the literature. This value is lower compared to other studies: for example, Winnik et al. [19] indicated a publication rate of $38 \%$, and Raptis et al. [20] indicated a rate of $40 \%$. However, our value is similar to the Yoon et al. [16] rate (30\%) and to the Chand et al. [18] rate (30\%). As example, the study of Chand et al. [18] retrieved all abstracts from the Scientific Meetings of the Cardiac Society of Australia and New Zealand from 1999 to 2005. Only $30 \%$ of the 2172 abstracts were followed by publication of a full-text article, and most publications were published within 1 (61\%) or 2 years $(84 \%)$.

Such diversity could be related to the differences in the study designs. In the clinical field, there are more frequent randomised clinical trials, which are subsequently published more easily than observational studies. As example, in regard to the surgical field, Raptis et al. [20] conducted an evaluation to assess the peer review process of the European Surgical Association from 2002 to 
Table 3 Full text publication vs unpublished papers $(\mathrm{N}=621)$

\begin{tabular}{|c|c|c|c|c|c|}
\hline & \multicolumn{2}{|c|}{$\begin{array}{l}\text { Full text } \\
\text { publication }\end{array}$} & \multicolumn{2}{|c|}{$\begin{array}{l}\text { Unpub- } \\
\text { lished }\end{array}$} & \multirow[t]{2}{*}{$p$ value } \\
\hline & $\mathrm{N}$ & $\%$ & $\mathrm{~N}$ & $\%$ & \\
\hline \multicolumn{6}{|l|}{ Affiliation } \\
\hline University & 120 & 28.4 & 302 & 71.6 & $<0.005$ \\
\hline Non Universitary hospitals & 3 & 3.2 & 90 & 96.8 & \\
\hline Local Public Health Institution & 5 & 15.2 & 28 & 84.8 & \\
\hline Other & 18 & 24.7 & 55 & 75.3 & \\
\hline \multicolumn{6}{|l|}{ Topics } \\
\hline Food and nutrition & 15 & 22.4 & 52 & 77.6 & $<0.005$ \\
\hline Environment & 13 & 27.7 & 34 & 72.3 & \\
\hline Health education & 21 & 21.6 & 76 & 78.4 & \\
\hline Chronic disease & 20 & 37.0 & 34 & 63.0 & \\
\hline Infectious disease & 16 & 18.4 & 71 & 81.6 & \\
\hline Dental hygiene & 5 & 71.4 & 2 & 28.6 & \\
\hline Hospital hygiene & 9 & 15.8 & 48 & 84.2 & \\
\hline Miscellaneous & 13 & 26.0 & 37 & 74.0 & \\
\hline Organization & 17 & 14.2 & 103 & 85.8 & \\
\hline Vaccine & 17 & 48.6 & 18 & 51.4 & \\
\hline \multicolumn{6}{|l|}{ Year } \\
\hline 2005 & 42 & 22.5 & 145 & 77.5 & 0.909 \\
\hline 2006 & 41 & 23.6 & 133 & 76.4 & \\
\hline 2007 & 63 & 24.2 & 197 & 75.8 & \\
\hline \multicolumn{6}{|l|}{ Abstract } \\
\hline Oral & 54 & 36.2 & 95 & 63.8 & $<0.005$ \\
\hline Poster & 92 & 19.5 & 380 & 80.5 & \\
\hline \multicolumn{6}{|l|}{ Geographic area } \\
\hline Northern Italy & 53 & 25.1 & 158 & 74.9 & 0.568 \\
\hline Central Italy & 60 & 21.5 & 219 & 78.5 & \\
\hline Southern Italy & 33 & 25.2 & 98 & 74.8 & \\
\hline \multicolumn{6}{|l|}{ First author gender } \\
\hline Male & 62 & 20.7 & 237 & 79.3 & 0.216 \\
\hline Female & 84 & 26.4 & 234 & 73.6 & \\
\hline \multicolumn{6}{|l|}{ Study design } \\
\hline Sperimental & 21 & 33.3 & 42 & 66.7 & 0.051 \\
\hline Observational descriptive & 47 & 18.5 & 207 & 81.5 & \\
\hline Observational analytical & 67 & 25.9 & 192 & 74.1 & \\
\hline Revision & 11 & 25 & 33 & 75 & \\
\hline \multicolumn{6}{|l|}{ Results } \\
\hline Negative & 4 & 9.8 & 37 & 90.2 & $<0.005$ \\
\hline Positive & 121 & 26.9 & 329 & 73.1 & \\
\hline Not evaluable & 21 & 16.3 & 108 & 83.7 & \\
\hline \multicolumn{6}{|l|}{ Sample size } \\
\hline$\leq 100$ & 47 & 21.4 & 173 & 78.6 & 0.342 \\
\hline$>100$ & 99 & 24.7 & 301 & 75.3 & \\
\hline \multicolumn{6}{|l|}{ Total score } \\
\hline Medium & 30 & 16.1 & 156 & 83.9 & $<0.005$ \\
\hline High & 78 & 24.0 & 248 & 76.0 & \\
\hline Very high & 38 & 35.0 & 71 & 65.0 & \\
\hline
\end{tabular}

Table 4 Multivariate analysis. Factors predicting publication $(\mathrm{N}=621)$

\begin{tabular}{|c|c|c|c|c|}
\hline & \multicolumn{4}{|c|}{ Multivariate regression } \\
\hline & $\mathrm{N}$ & $\begin{array}{l}\text { Odds } \\
\text { ratio }\end{array}$ & $\begin{array}{l}95 \% \\
\mathrm{Cl}\end{array}$ & $P$ value \\
\hline \multicolumn{5}{|l|}{ Affiliation } \\
\hline University & 120 & 1 & - & - \\
\hline $\begin{array}{l}\text { Local Public Health institu- } \\
\text { tion }\end{array}$ & 5 & 0.64 & $(0.22-1.85)$ & 0.418 \\
\hline Non universitari Hospitals & 3 & 0.09 & $(0.03-0.33)$ & $<0.001$ \\
\hline Other & 18 & 0.91 & $(0.49-1.70)$ & 0.773 \\
\hline \multicolumn{5}{|l|}{ Topics } \\
\hline Food and nutrition & 15 & 1 & - & - \\
\hline Environment & 13 & 1.24 & $(0.50-3.09)$ & 0.638 \\
\hline Health education & 21 & 0.94 & $(0.42-2.13)$ & 0.897 \\
\hline Chronic disease & 20 & 1.91 & $(0.80-4.60)$ & 0.145 \\
\hline Infectious disease & 16 & 0.78 & $(0.34-1.80)$ & 0.564 \\
\hline Dental hygiene & 5 & 10.52 & $(1.47-75.18)$ & 0.019 \\
\hline Hospital hygiene & 9 & 0.77 & $(0.29-2.04)$ & 0.600 \\
\hline Miscellaneous & 13 & 1.73 & $(0.67-4.42)$ & 0.254 \\
\hline Organization & 17 & 0.71 & $(0.31-1.63)$ & 0.419 \\
\hline Vaccine & 17 & 3.45 & $(1.32-9.00)$ & 0.011 \\
\hline \multicolumn{5}{|l|}{ Abstract } \\
\hline Oral & 54 & 1 & - & - \\
\hline Poster & 92 & 0.60 & $(0.37-0.99)$ & 0.044 \\
\hline \multicolumn{5}{|l|}{ First author gender } \\
\hline Male & 62 & 1 & - & - \\
\hline Female & 84 & 1.31 & $(0.86-1.99)$ & 0.212 \\
\hline \multicolumn{5}{|l|}{ Study design } \\
\hline Sperimental & 21 & 1 & - & - \\
\hline Observational descriptive & 47 & 0.74 & $(0.36-1.52)$ & 0.415 \\
\hline Observational analytical & 67 & 1.08 & $(0.56-2.08)$ & 0.820 \\
\hline Revision & 11 & 1.12 & $(0.43-2.93)$ & 0.820 \\
\hline \multicolumn{5}{|l|}{ Results } \\
\hline Negative & 4 & 1 & - & - \\
\hline Positive & 121 & 3.43 & $(1.03-11.4)$ & 0.044 \\
\hline Not evaluable & 21 & 2.23 & $(0.61-8.17)$ & 0.228 \\
\hline \multicolumn{5}{|l|}{ Total score } \\
\hline Medium & 30 & 1 & - & - \\
\hline High & 78 & 1.60 & $(0.94-2.72)$ & 0.086 \\
\hline Very high & 38 & 2.72 & $(1.39-5.31)$ & 0.003 \\
\hline
\end{tabular}

2007. Approximately one-third of the contributions were accepted for presentation at the annual meetings and, of those, $40 \%$ were published in Annals of Surgery. The authors found, accordingly with the previous hypothesis, only two independent factors able to promote subsequent publication: randomised controlled trials as the study design and a sample size with more than 100 patients.

Other good quality abstracts do not reach publication, in our opinion, for logistical or qualitative reasons. 
Logistical reasons could be due to various possibilities: (1) "Lack of time" for the preparation of a full manuscript text (e.g., for professionals employed in non universitary hospitals). (2) Losing confidence when results are not clinically or statistically significant $[22,29]$. (3) Other papers have similar findings. Qualitative reasons include inadequate study design, methodology or grammatical style, including language barriers, which may prevent the work from surviving the peer review process.

Our results are different than those of Gorman et al. [11], who concluded that only $36 \%$ of abstracts presented in Toxicology Meetings were published in peer review journals.

Regarding the overall mean impact factor, the Yoon et al. study [16] reported a value for published research of 2.90. Thus, the overall publication rate was relatively low compared not only with other urological meetings held in America and Europe but also with the SItI Conferences.

Conversely, Winnik et al. [19] indicated that the works presented to the European Society of Cardiology Congress reached very high impact factor values: approximately $40 \%$ of the abstracts were placed over 5 . In this case, however, the types of works presented include Randomized Clinical Trials, meta-analyses and systematic reviews that are almost absent in our sample and the fact that Public Health Journals have, usually, a lower IF than clinical ones.

The distribution of time to publication for abstracts was consistent with previous studies of publication, occurring within $2-3$ years $[16,17,30,31]$.

The analyses revealed a significant disadvantage for non-university-affiliated institutions. The reasons behind this difference may result from a greater willingness and ability of academic professionals compared to hospital ones in conducting and directing the different steps that range from abstract to publication. It must be noted that this result is in agreement with the conclusions reached by other authors [19, 32]. Winnik et al. [19], as example, performed a 4-year follow-up of the abstracts submitted to the European Society of Cardiology Congress in 2006 in order to identify factors predicting high-quality research. In their study they found that $38 \%$ of all accepted studies were subsequently published and that the presence of an academic affiliation and a prospective study design were associated with full-text publication.

Moreover, from the analysis, it emerges that certain Conference topics predispose the studies to an increased likelihood of publication. This result can be partially explained by the fact that both the topics (Dental hygiene and Vaccine) are, on one hand, more subjected to clinical trial and, on the other, not strictly related to national settings.
Regarding oral presentation, most authors did not analyze this item $[5,18]$ or because the study design $[10,11$, 13] or because they were not able to distinguish whether the study was presented as a poster or podium presentation [16]. Winnik [19] analyzed the abstracts presentation type but did not find any statistical correlation. Otherwise, according to our findings, Krzyzanowska [9] found that studies with oral or plenary presentation were published sooner than those not orally presented $(p=0.002)$ and also Schnatz [17] wrote that the average time to publication for oral presentations was $1.7 \pm 1.3$ years, while for poster presentations was $2.0 \pm 1.5$ years $(\mathrm{P}=0.241)$. The publication rate of oral presentations was significantly higher than the poster presentations rate (57.7 vs $36.5 \%$; $<0.003)$.

We may assume that the research that is presented orally may be judged by the reviewers as having greater interest and clinical relevance along with more sound methodology and better results.

In the literature, few authors have analysed how gender could affect the success of authors submitting posters or abstracts [19].

Interestingly, the rate of full-text publication of male authors seemed lower compared with their female colleagues ( 20.7 vs. $26.4 \%$ ), but in the multivariate analysis no statistical significance was found for the gender in predicting full-text publication.

Our results differ from those of Winnik et al. [19] in that, in the cardiology field, the female gender was identified as a factor that negatively affects scientific success.

Of course, all of the above findings should be interpreted cautiously and considered exploratory. The importance of understanding the role of gender in research is critical and certainly requires further consideration.

No statistically significant differences were identified regarding the study designs of abstracts included in our analysis. This result is quite interesting, considering the peculiarities of public health field, where very often the papers published are not comprehensive of numeric data but instead related to organizational perspectives or policies discussion.

Abstracts that claim to have achieved results positive and consistent with objectives are more likely to be published (adjusted OR 3.43). This result might suggest that scientific journals tend to prefer works with positive results or that authors themselves are inclined to send such works to editors, making a selection a priori and focusing on more appealing studies. These types of behaviours certainly promote the publication bias.

Regarding the abstract quality score, a positive trend emerges: with the score increasing, there is a higher probability that the work is published in extenso. This result shows that the evaluation method applied has a 
high degree of agreement with the scientific journal editors' opinions and judgments.

\section{Limitations and further studies}

This study has some limitations that deserve discussion. First of all, our search algorithm could potentially miss some papers that may have been published in journals not listed on Medline. It is known that Medline lists up to $80 \%$ of the total journal articles published worldwide [33]. Moreover, if the authors, the title or the hypothesis of the study were substantially modified during the process of editing and supplementing the data, our algorithm may have not detected the article in our search. However, we tried to limit this phenomenon by performing very thorough research.

A potential limitation is represented by the choice to include only high quality abstracts in our analysis. However, we declared this selection strategy as main inclusion criteria in the aim and in the methods section of the study.

\section{Conclusions}

Authors have an ethical obligation to endeavour in the distribution of their original findings through scientific publication, consequently improving the quality of scientific research. Once available to the public and to other health professionals, this research can be followed up and implemented in the best interest of the patient [34].

To make a useful and precise selection, it is necessary to know the main features related to the publication, and the data presented in this study provide a good framework.

It would be interesting, through further research, to survey the abstract authors to identify reasons for unpublished data and to learn what percentage is due to logistical versus qualitative reasons. As part of that follow-up, analysis of funding type, the country from which the research originated, pharmaceutical company involvement or support, clinical versus laboratory studies or other potential biases for publication could be assessed to evaluate whether they affect either the likelihood of or time to publication. Insight into reasons for delays and the number of submissions until publication would also be informative.

\footnotetext{
Authors' contributions

SC has made substantial contributions to conception and design, to revise it critically for important intellectual content and to give final approval of the version to be published. GM has been involved in drafting the manuscript and have made substantial contributions to acquisition of data, analysis and interpretation of data. TW has been involved in drafting the manuscript and have made substantial contributions to acquisition of data, analysis and interpretation of data. FB has made substantial contributions to revising it critically for important intellectual content. RS has made substantial contributions to conception and design, to revise it critically for important intellectual content and to give final approval of the version to be published. All authors read and approved the final manuscript.
}

\section{Author details}

${ }^{1}$ Post Graduated School in Public Health, University of Milan, Milan, Italy.

${ }^{2}$ Department of Public Health, Post Graduated School in Public Health, University of Turin, Via Santena 5/bis, 10126 Turin, Italy. ${ }^{3}$ Department of Public Health, University of Turin, Turin, Italy.

\section{Acknowledgements}

None declared.

This work was not supported by any research fund.

Compliance with ethical guidelines

\section{Competing interests}

The authors declare that they have no competing interests.

Received: 23 September 2013 Accepted: 21 September 2015 Published online: 29 September 2015

\section{References}

1. Fisher M, Friedman SB, Strauss B. The effects of blinding on acceptance of research papers by peer review. JAMA. 1994;272:143-6.

2. Garfunkel JM, Ulshen MH, Hamrick HJ, Lawson EE. Effect of institutional prestige on reviewers' recommendations and editorial decisions. JAMA. 1994;272:137-8.

3. Olson CM, Rennie D, Cook D, Dickersin K, Flanagin A, Hogan JW, Zhu Q, Reiling J, Pace B. Publication bias in editorial decision making. JAMA. 2002;287:2825-8.

4. Kemper KJ, McCarthy PL, Cicchetti DV. Improving participation and interrater agreement in scoring ambulatory pediatric association abstract. How well have we succeeded? Arch Pediatr Adolesc Med. 1996;150:380-3.

5. Lin JM, Bohland JW, Andrews P, et al. An analysis of the abstracts presented at the annual meetings of the Society for Neuroscience from 2001 to 2006. PLoS One. 2008;3:e2052.

6. Poolman RW, Keijser LCM, de Waal Malefijt MC, et al. Reviewer agreement in scoring 419 abstracts for scientific orthopedics meetings. Acta Orthop. 2007;78(2):278-84.

7. Bhandari M, Templeman D, Tornetta P. Interrater reliability in grading abstracts for the orthopaedic trauma association. Clin Orthop Relat Res. 2004;423:217-21.

8. Van Der Steen LP, Hage JJ, et al. Department of Plastic and Reconstructive Surgery, Antoni van Leeuwenhoek Hospital: Reliability of a structured method of selecting abstracts for a plastic surgical scientific meeting. Plast Reconstr Surg. 2003;111:2215-22.

9. Krzyzanowska MK, Pintilie M, Tannock IF. Factors associated with failure to publish large randomized trials presented at an oncology meeting. JAMA. 2003;290:495-501.

10. Callaham ML, Wears RL, Weber EJ, Barton C, Young G. Positive-outcome bias and other limitations in the outcome of research abstracts submitted to a scientific meeting. JAMA. 1998;280(3):254-7.

11. Gorman RL, Oderda GM. Publication of presented abstracts at annual scientific meetings: a measure of quality? Vet Hum Toxicol. 1990;32(5):470-2.

12. Juzych MS, Shin DH, Coffey J, Juzych L, Shin D. Whatever happened to abstracts from different sections of the association for research in vision and ophthalmology? Invest Ophthalmol Vis Sci. 1993;34(5):1879-82.

13. Toma M, McAlister FA, Bialy L, Adams D, Vandermeer B, Armstrong PW. Transition from meeting abstract to full-length journal article for randomized controlled trials. JAMA. 2006;295(11):1281-7.

14. Yentis SM, Campbell FA, Lerman J. Publication of abstracts presented at anaesthesia meetings. Can J Anaesth. 1993;40(7):632-4

15. Preston CF, Bhandari M, Fulkerson E, Ginat D, Egol KA, Koval KJ. The consistency between scientific papers presented at the Orthopaedic Trauma Association and their subsequent full-text publication. J Orthop Trauma. 2006;20(2):129-33.

16. Yoon PD, Chalasani V, Woo HH. Conversion rates of abstracts presented at the Urological Society of Australia and New Zealand (USANZ) Annual Scientific Meeting into full-text journal articles. BJU Int. 2012;110(4):485-9. 
17. Schnatz PF, Romegialli A, Abrantes J, Marakovits K, Cunningham D, O'Sullivan DM. North American Menopause Society: The North American Menopause Society: from abstract to publication. Menopause. 2008;15(5):996-1001.

18. Chand V, Rosenfeldt FL, Pepe S. The publication rate and impact of abstracts presented at the Cardiac Society of Australia and New Zealand (1999-2005). Heart Lung Circ. 2008;17(5):375-9.

19. Winnik S, Raptis DA, Walker JH, Hasun M, Speer T, Clavien PA, Komajda M, Bax JJ, Tendera M, Fox K, Van de Werf F, Mundow C, Lüscher TF, Ruschitzka F, Matter CM. From abstract to impact in cardiovascular research: factors predicting publication and citation. Eur Heart J. 2012;33(24):3034-45.

20. Raptis DA, Oberkofler CE, Gouma D, Garden OJ, Bismuth H, Lerut T, Clavien PA. Fate of the peer review process at the ESA: long-term outcome of submitted studies over a 5-year period. Ann Surg. 2010;252(5):715-25

21. Bhandari M, Devereaux PJ, Guyatt GH, Cook DJ, Swiontkowski MF, Sprague S, Schemitsch EH. An observational study of orthopaedic abstracts and subsequent full-text publications. J Bone Jt Surg Am. 2002;84-A(4):615-21.

22. Sprague S, Bhandari M, Deveraux PJ, et al. Barriers to full-text publication following presentation of abstract annual orthopaedic meetings. J Bone Jt Surg Am. 2003;85:158-63.

23. Scherer RW, Langenberg P, von Elm E. Full publication of results initially presented in abstracts. Cochrane Database Syst Rev. 2007;18(2). doi:10.1002/14651858.MR000005.pub3.

24. Scherer RW, Dickersin K, Langenberg P. Full publication of results initially presented in abstracts. A meta-analysis. JAMA. 1994;272:158-62.

25. Von Elm E, Costanza MC, Walder B, Tramèr MR. More insight into the fate of biomedical meeting abstracts: a systematic review. BMC Med Res Methodol. 2003;10(3):12.
26. Vecchi S, Belleudi V, Amato L, Davoli M, Perucci CA. Does direction of results of abstracts submitted to scientific conferences on drug addiction predict full publication? BMC Med Res Methodol. 2009;8(9):23.

27. Castaldi S, Colombo A, D'Errico R, Bert F, Siliquini R and study group. Study for the quality assessment of abstracts presented to Italian public health national conferences: a 6 years survey. Ann Ig. 2013;25(5):377-87.

28. Hosmer DW, Lemeshow S. Applied logistic regression (Wiley Series in probability and statistics). 2nd ed. New York: John Wiley \& Sons Inc.; 2000.

29. Weber EJ, Callaham ML, Wears RL, Barton C, Young G. Unpublished research from a medical specialty meeting: why investigators fail to publish. JAMA. 1998:280:257-9.

30. $\mathrm{Ng} \mathrm{L}$, Hersey K, Fleshner N. Publication rate of abstracts presented at the annual meeting of the American Urological Association. BJU Int. 2004;94:79-81.

31. Smith WA, Cancel QV, Tseng TY, Sultan S, Vieweg J, Dahm P. Factors associated with the full publication of studies presented in abstract form at the annual meeting of the American Urological Association. J Urol. 2007;177:1084-9.

32. Eloubeidi MA, Wade SB, Provenzale D. Factors associated with acceptance and full publication of $\mathrm{Gl}$ endoscopic research originally published in abstract form. Gastrointest Endosc. 2001;53:275-82.

33. Timmer A, Blum T, Lankisch PG. Publication rates following pancreas meetings. Pancreas. 2001;23:212-5.

34. Chalmers I. Underreporting research is scientific misconduct. JAMA. 1990;263:1405-8

\section{Submit your next manuscript to BioMed Central and take full advantage of:}

- Convenient online submission

- Thorough peer review

- No space constraints or color figure charges

- Immediate publication on acceptance

- Inclusion in PubMed, CAS, Scopus and Google Scholar

- Research which is freely available for redistribution

Submit your manuscript at

www.biomedcentral.com/submit

C) Biomed Central 